Pesquisa em Foco ISSN (2176-0136)

http://ppg.revistas.uema.br/index.php/PESQUISA EM FOCO

São Luís, v. 22, n. 2, Jul./Dez. 2017

\title{
CONCEITOS, FUNÇÕES E INSTRUMENTOS SOBRE AVALIAÇÃO DA APRENDIZAGEM: QUAIS AS CONCEPÇÕES DE PROFESSORES DE UMA ESCOLA EM TIMON (MA)?
}

Tiago Rodrigues da Silva ${ }^{1}$, Beatriz Bacelar Barbosa ${ }^{1}$, Odaléia Alves da Costa ${ }^{2}$

\section{RESUMO}

O presente artigo tem como objetivo analisar a avaliação da aprendizagem praticada na escola pública-estadual, Centro de Ensino Senador Clodomir Millet, na cidade de Timon, Maranhão através das concepções de professores situando-as em relação aos conceitos, funções, instrumentos e práticas da ação avaliativa. Na metodologia, adotou-se uma abordagem metodológica de caráter qualitativa e descritiva por meio de pesquisas bibliográficas e de entrevistas semiestruturas com três professores: dois do gênero masculino e uma do feminino. Os resultados obtidos apontaram para a avalição escolar como uma medida de verificação da aprendizagem dos discentes atribuindo o ato avaliativo, a função somativa. As provas escritas constituem o principal instrumento para a avaliação quantitativa e os critérios de notas centralizados também em fatores qualitativos. Constatou-se a que a instituição escolar, em geral, propõe uma avaliação visando à classificação dos alunos em reprovados e aprovados e um exercício avaliativo estático. Desse modo, o estudo apresentou uma exploração da avaliação da aprendizagem traçando paralelos entre a teoria e a prática, assim, levantando discussões e reflexões sobre a ação pedagógica avaliativa como um ato de reorganização de ensino para os professores.

Palavras-chave: Avaliação da aprendizagem; Ensino e Aprendizagem; Professores.

\footnotetext{
${ }^{1}$ Graduados em Licenciatura em Ciências Biológicas pelo Instituto Federal de Educação, Ciência e Tecnologia do Maranhão. Campus Timon. Brasil E-mails: thiago2581@hotmail.com/ beatrizbacelar_@hotmail.com

${ }^{2}$ Professora da Área de Educação do Instituto Federal de Educação, Ciência e Tecnologia do Maranhão. Campus Timon. Brasil. Doutora em Educação pela Universidade de São Paulo. E-mail: odaleia@ifma.edu.br,
} 


\title{
CONCEPTS, FUNCTIONS AND INSTRUMENTS ON LEARNING EVALUATION: WHAT ARE THE CONCEPTIONS OF SCHOOL TEACHERS IN TIMON (MA)?
}

\begin{abstract}
The present article aims to analyze the evaluation of the learning practiced in the publicstate school, Senador Clodomir Millet Teaching Center, in the city of Timon, Maranhão, through the conceptions of teachers, situating them in relation to concepts, functions, instruments and practices evaluation action. In the methodology, a qualitative and descriptive methodological approach was adopted through bibliographical research and semi-structured interviews with three teachers: two men and one woman. The results obtained point to the evaluation of the school as a measure of verification of the students' learning, attributing the act of evaluation, the summative function. Written tests are the main instrument for quantitative assessment and criteria for centralized grades also on qualitative factors. It was verified that the school institution, in general, proposes an evaluation aiming at the classification of the students in disapproved and approved ones and a exercise of static evaluation. Thus, the study presented an exploration of the evaluation of learning, drawing parallels between theory and practice, raising discussions and reflections on the pedagogical action of evaluation as an act of reorganization of teaching for teachers.
\end{abstract}

Keywords: Learning assessment; Teaching and learning; Teachers.

\section{INTRODUÇÃO}

A avaliação da aprendizagem tem como objetivo compreender os percursos do aprendizado dos alunos, mediante os seus resultados. Através disso, traduz também as definições, práticas e instrumentos avaliativos adotados pelo professor em sala de aula. Considera-se, desse modo, a avaliação como uma forma de analisar não somente os avanços e dificuldades dos discentes, mas também uma oportunidade do docente (re) pensar criticamente o seu trabalho pedagógico. 
Pesquisa em Foco ISSN (2176-0136)

http://ppg.revistas.uema.br/index.php/PESQUISA EM FOCO

São Luís, v. 22, n. 2, Jul./Dez. 2017

Entretanto, as práticas correntes da avaliação nas escolas e salas de aula dão peso exclusivamente aos conhecimentos descontextualizados e muito pouco para um ato avaliativo que busca auxiliar a construção de conhecimentos dos alunos, dessa forma, a avaliação na educação torna-se um concurso de excelência dos estudantes, professores e escolas (PERRENOUD, 1999).

Diante dessas considerações, a avaliação educacional configura-se como afirma Luckesi (2011) uma temática recorrente em pesquisas educacionais, uma vez que ocorre a necessidade de aprofundar as concepções dessa atividade pedagógica, no que diz respeito aos professores e alunos (HAYDT, 2004; GRILLO; LIMA, 2010). De tal forma, a avaliação continua sendo ponto vulnerável, exigindo, consequentemente, maiores reflexões.

Desse modo, de acordo com André e Passos (2011) as investigações didáticas das práticas avaliativas proporcionam discussões, reflexões e autocorreção do processo de ensino e aprendizagem dos alunos e professores. Portanto, continua sendo com frequência objeto de estudo pelos pesquisadores de avaliação (SAUL, 2010; FREITAS; COSTA; MIRANDA, 2014).

Tendo isto em vista, e considerando a prática avaliativa como principal instrumento de diagnóstico e de reorganização do ensino e aprendizagem pela compreensão do exercício docente, o trabalho é centralizado na seguinte problemática: quais são os conceitos, funções, instrumentos e práticas da avaliação da aprendizagem de professores da escola estadual Centro de Ensino Senador Clodomir Millet da cidade de Timon, Maranhão?

O presente artigo, portanto, tem como objetivo descrever e analisar a avaliação da aprendizagem praticada na escola Centro de Ensino Senador Clodomir Millet, através das concepções de três professores (dois homens e uma mulher) situando-as em relação as suas práticas avaliativas. Busca contribuir com maiores compreensões acerca da avaliação em seus aspectos teóricos e práticos. 


\section{A AVALIAÇÃO NO PROCESSO DE ENSINO E APRENDIZAGEM}

Na centralidade da análise do processo de ensino e aprendizagem na sala de aula a avaliação da aprendizagem ganha seu destaque, uma vez que reflete não somente o aprendizado do aluno, mas também os percursos metodológicos do educador. A avaliação, diante disso, em parceria com o ensino e aprendizagem, constituem uma ação pedagógica, e devem ambos ser considerados como uma totalidade.

Desse modo, a avaliação auxilia tanto os alunos como os professores sobre o andamento do ensino em sala de aula, sendo de responsabilidade dos docentes colocarem a prática avaliativa a serviço das aprendizagens, com isso, o avaliar deve proporcionar o aprender dos educandos. Nesse contexto, a avaliação deve ser usada no sentido de planejar ações educativas futuras (HOFFMANN, 2008). Logo,

avaliar envolve um conjunto de procedimentos didáticos cuja finalidade é acompanhar o aluno em seu percurso de aprendizagem, durante o qual ocorrem avanços e/ou retrocessos em múltiplas dimensões. Avaliar é acompanhar o processo de construção do conhecimento (HOFFMANN, 2008, p. 152).

Nessa visão, as práticas da avaliação da aprendizagem precisam estar pautadas em preceitos epistemológicos, filosóficos e práticos do construtivismo. Desse modo, o avaliador deve ir além da sistematização quantitativa das notas, mas precisa intervir na situação como uma forma de contribuir para o desenvolvimento do aluno (FREITAS; COSTA; MIRANDA, 2014). Com efeito, caracteriza as aplicações da avaliação da aprendizagem durante o ensino como uma das atividades complexa no processo educativo (GRILLO; LIMA, 2010). Além disso, formula compromissos políticos e éticos, bem como segundo Gonçalves e Larcher (2011), variáveis pedagógicas e sociais.

A Lei de Diretrizes e Bases da Educação Nacional - Lei 9394/1996 que estabelece a avaliação como uma verificação da aprendizagem em seus aspectos qualitativos e quantitativos dos resultados ao longo dos períodos letivos, bem como menciona eventuais provas como instrumento para quantificação (BRASIL, 1996). Como tal, a avaliação é constituída a partir do compromisso político na qual busca um desenvolvimento da aprendizagem e cidadania dos educandos através de aplicações 
Pesquisa em Foco ISSN (2176-0136)

http://ppg.revistas.uema.br/index.php/PESQUISA EM FOCO

São Luís, v. 22, n. 2, Jul./Dez. 2017

sistemáticas de avaliações, nesse caso, porém o ato avaliativo é aplicado verdadeiramente como exames pontuais.

Contudo, o fato de estar estabelecida na lei não significa a garantia de mudanças nas práticas dos docentes e instituições de ensino. Por sua vez, o comprometimento ético segundo Grillo e Lima (2010) é fundado no princípio do respeito, da solidariedade e do bem coletivo, pois os resultados das avaliações formais causam forte impacto na autoimagem e na autoestima do estudante.

O suporte epistemológico do ato de avaliação no exercício pedagógico conforme Haydt (2004) é associado a outros termos, tais como: notas, sucesso, fracasso, promoção e repetência, além disso, a autora descreve que os procedimentos avaliativos são referidos como uma verificação do nível de aprendizagem dos alunos. No entanto, em decorrências de novas concepções, a atividade avaliativa assume dimensões mais amplas determinadas pelas percepções que fundamentam a proposta de ensino, como é verificado em Mizukami (2011) ao destacar características avaliativas em diferentes abordagens de ensino.

De maneira similar, Gonçalves e Larchert (2012) discutem que a avalição da aprendizagem na concepção educativa não possui apenas uma perspectiva de teoria e prática, muito menos um consenso por todos os educadores, o que se tem é uma variedade de formas, funções e instrumentos para realizar o ato avaliativo da aprendizagem dos alunos.

Ao discutir as definições teóricas e práticas de avaliação educacional Luckesi (2011) a menciona como uma ação de investigação do professor, cujo sentido é intervir na busca dos melhores resultados do processo de aprendizagem nos alunos, em sala de aula. Em seu conceito, afirma que a avaliação é um juízo de qualidade sobre dados relevantes para uma tomada de decisão, sendo assim, abordando a educação como ferramenta de transformação social.

O conceito da avaliação para Hoffmann (2008) representa algo dinâmico e contínuo para a reorientação das práticas avaliativas. Tem-se, assim, que a avaliação orienta tanto o professor, com uma auto-avaliação de seu ensino, como o aluno. No caso dos educadores permite uma reflexão sobre a sua prática pedagógica (objetivos 
estabelecidos, didática e resultados obtidos) e orienta a tomada de decisões pertinentes para a continuidade dos aspectos metodológicos do trabalho docente (ANDRÉ; PASSOS, 2011).

\section{PERCURSOS METODOLÓGICOS}

A abordagem do estudo foi de cunho descritivo e qualitativo, procurando descrever e analisar o perfil do professor quando se trata da avaliação da aprendizagem utilizada em seu trabalho docente. Por isso, as concepções dos professores permitem compreender o cenário da avaliação da aprendizagem exercida na instituição de ensino. Isso na visão de Triviños (2015) possibilita a interpretação dos resultados como totalidade da percepção de um fenômeno no contexto educacional.

Partindo desses pressupostos, os percursos metodológicos do estudo seguiram com a pesquisa bibliográfica. Definida por Fonseca (2002) como o ato de investigar os conhecimentos publicados sobre a problemática do qual se procura a resposta. A construção do referencial teórico partiu da base epistemológica dos conceitos, funções e instrumentos da avaliação da aprendizagem em sala de aula.

Em seguida, ocorreram as coletas de dados na escola estadual de Ensino Médio, Centro de Ensino Senador Clodomir Millet, localizada na cidade de Timon, Maranhão, região Nordeste do Brasil. O referido município está localizado a 446 km de São Luís, capital do Estado, e situado ao lado da cidade de Teresina, capital do Estado do Piauí, da qual faz parte de sua região metropolitana.

O interesse em investigar a avaliação da aprendizagem a partir da perspectiva dos professores do Centro de Ensino Senador Clodomir Millet foi em decorrência da soma de suas taxas de aprovação para as três séries de o Ensino Médio resultar em cerca 80\%, conforme o Instituto Nacional de Estudos e Pesquisas Educacionais Anísio Teixeira (INEP) (BRASIL, 2013). No geral, a instituição escolar locus da investigação, a partir dos estudos de Costa, Castro e Almeida Neto (2015), dentre as sete escolas estaduais da cidade de Timon, ocupa o terceiro lugar em taxa de aprovação para o Ensino Médio.

As coletas de dados ocorreram nos meses de abril e maio de 2015 e como técnica e instrumento para isso se fez o uso de entrevistas semiestruturadas definidas como 


\section{Pesquisa em Foco ISSN (2176-0136)}

http://ppg.revistas.uema.br/index.php/PESQUISA EM FOCO

São Luís, v. 22, n. 2, Jul./Dez. 2017

"uma série de questionamentos básicos, apoiados em teorias e hipóteses, que interessam a pesquisa" (TRIVIÑOS, 2015, p. 146). Além disso, permite uma conversa com o indivíduo com a utilização de um roteiro definido acerca dos principais pontos investigados, e prevê também eventuais indagações (FONSECA, 2002).

Para tanto, adotou-se como auxílio a adaptação das perguntas por Preite (2010) sobre as concepções de professores da rede pública de ensino no que diz respeito da avaliação no ensino e aprendizagem. Com isso, foram abordadas sete perguntas que exploram os conceitos, instrumentos, funções, critérios e incômodos no processo avaliativo.

As concepções e saberes evocados pelos sujeitos da pesquisa foram analisados a partir dos fundamentos teóricos adotados na pesquisa. Em vista disso, as interpretações dos resultados subjetivos dos indivíduos envolvidos no estudo surgem como uma totalidade da percepção de um fenômeno em um determinado contexto (TRIVIÑOS, 2015).

Triviños (2015) afirma que nas pesquisas qualitativas podem ser utilizados recursos aleatórios para a fixação de sua amostra, uma vez que não se apoia tanto em dados estatísticos para a determinação de sua representatividade, o que se deve buscar é uma pequena representação do grupo maior que integram como sujeitos da pesquisa.

A partir disso, foram estabelecidos os seguintes critérios para selecionar os sujeitos participantes do estudo: tempo de docência de no mínimo 10 anos e disponibilidade para a entrevista. Com os indicadores definidos, obtiveram-se três sujeitos para a pesquisa, como descreve a Tabela 1.

Tabela 01 - Relação dos sujeitos da pesquisa.

\begin{tabular}{cccc}
\hline Professores & Graduação & Gênero & $\begin{array}{c}\text { Tempo de } \\
\text { docência }\end{array}$ \\
\hline A & Matemática & Masculino & 15 \\
B & $\begin{array}{c}\text { Português e } \\
\text { Artes }\end{array}$ & Feminino & 11 \\
C & $\begin{array}{c}\text { Ciências } \\
\text { Biológicas }\end{array}$ & Masculino & 25 \\
\hline
\end{tabular}

Fonte: Elaboração própria. 
Com a finalidade de preservação dos professores envolvidos na pesquisa os sujeitos foram denominados de A, B e C cuja finalidade do estudo também foi atender as diretrizes éticas previstas nas Normas de Realização de Pesquisa em Seres Humanos, resolução no 510/2016 do Conselho Nacional de Saúde. Para tanto, as participações foram voluntárias, e somente possíveis após o preenchimento do Termo de Consentimento Livre e Esclarecido.

\section{RESULTADOS E DISCUSSÕES}

Na intenção de compreender o significado da avaliação e como isso influencia no trabalho pedagógico dos professores, o conjunto de questionamentos recolhidos ao longo da entrevista, inicialmente indagou sobre: o que significa avaliar?

$\mathrm{Na}$ percepção dos 03 professores a avaliação é uma forma de medir a aprendizagem. Logo, a avaliação como processo de medida é caracteriza para Luckesi (2011) como a primeira ação para compreender e decidir os futuros passos da estimativa da aprendizagem dos discentes.

Haydt (2004) descreve que a avalição com uso do termo medir reflete concepções pedagógicas que o ato avaliativo é puramente para a quantificação de resultados.

A ideia de medição na avalição é também uma forma de realizar comparações tomando como padrão outros objetivos a serem medidos (LUCKESI, 2011). Essa definição apresenta que, na maioria das vezes, os professores podem expressar olhares diferenciados para suas turmas tendo como base o quanto a medida da aprendizagem dos discentes alcançou ou não os resultados esperados (GONÇALVES; LARCHERT, 2012).

Quando a avaliação pelos professores sujeitos da pesquisa caracteriza-se como uma forma de medir, dimensionar, quantificar o aproveitamento da aprendizagem de seus alunos reflete, de acordo com Gonçalves e Larchert (2012) para uma abordagem tecnicista do processo avaliativo. Desse modo, está centralizado para a produtividade do aluno, ou seja, o interesse é na capacidade do estudante em aprender a fazer e executar. Na qual a única preocupação são os resultados finais e a comprovação dos 
Pesquisa em Foco ISSN (2176-0136)

http://ppg.revistas.uema.br/index.php/PESQUISA EM FOCO

São Luís, v. 22, n. 2, Jul./Dez. 2017

objetivos estabelecidos pelos cronogramas e, às vezes, desconsiderando os interesses e necessidades individuais dos alunos (SAUL, 2010).

A avaliação, nesse sentido, é tradicionalmente para aquisição dos conhecimentos mínimos e certificação para terceiros, o que proporciona o funcionamento do sistema escolar (PERRENOUD, 1999). Visualizando dessa forma, a avaliação leva a um quadro de informação dos alunos aptos para passar para o próximo ano letivo ou unidade didática. Dessa forma, enquanto instrumento de medição, necessariamente não expressa a aprendizagem dos alunos, tendo em vista, que para tal devem ser considerados outros aspectos além do puramente quantitativo.

Quanto à função da avaliação no trabalho dos professores, que permeia relações diretas com os seus significados nos processos de ensino e aprendizagem, averiguou-se se os professores: consideram necessário avaliar os alunos? Por quê?

As respostas obtidas foram de maneiras distintas, sendo que o professor $A$, considera a avaliação como um parâmetro para verificar se o trabalho realizado em sala de aula está obtendo seus devidos resultados. A educadora B argumentou seu uso como uma forma de preparar os alunos para as avaliações do sistema de educação, tais como o Exame Nacional do Ensino Médio (ENEM), olímpiadas de conhecimento (Língua Portuguesa, Matemática, etc).

Percebe-se que os professores A e B apresentam concepções da avaliação da aprendizagem dentro do contexto de verificação. Nesse aspecto, Luckesi (2011) afirma que tradicionalmente as escolas brasileiras atuam com a verificação, o que traduz que o objetivo da avaliação da aprendizagem é somente observar os resultados naquilo que "é" ou "não é". Desse modo, expressa que não ocorrem análises dados, congelando os resultados dos alunos sem a atribuição de novos significados.

Para Hoffmann (2008) isso é reflexo de uma visão epistemológica da avaliação como um ato de instrução em que se pese a valorização da memorização dos alunos concebendo apenas uma aprendizagem mecânica e sem significados. Com tais fundamentos teóricos não ocorre, de fato, uma orientação do aluno no sentido de sua construção de conhecimento com pressupostos teóricos do construtivismo. 
O professor C relatou que é necessário avaliar os alunos para saber qual conhecimento de mundo os discentes possuem da disciplina com uma visão de interdisciplinaridade. Como efeito, esse processo avaliativo visa verificar a existência, ou ausência, de habilidades e conhecimentos pré-estabelecidos necessários para novas aprendizagens, ou seja, sua bagagem cognitiva (SANTOS, 2005).

De fato, o processo de verificar estabelece apenas a forma classificatória dispensando tomadas de atitudes a partir dos resultados alcançados. $\mathrm{O}$ ato avaliativo torna-se meramente um instrumento estático e classificatório, indicando uma análise superficial do processo de ensino e, portanto, não influencia significativamente no avanço da aprendizagem dos alunos.

Diante do exposto até aqui, com base em Haydt (2004) elaborou-se um Quadro 1, em que se apresentam as funções diferenciadas dos propósitos da ação avaliativa.

Quadro 1 - Funções e modalidades da avaliação.

\begin{tabular}{|c|c|l|}
\hline Função & Modalidade & \multicolumn{1}{|c|}{ Propósito } \\
\hline Diagnóstica & Diagnosticar & $\begin{array}{l}\text { Detectar dificuldades específicas de aprendizagem, } \\
\text { tentando identificar suas causas. }\end{array}$ \\
\hline Somativa & Classificar & $\begin{array}{l}\text { Classificar os resultados de aprendizagem } \\
\text { alcançados pelos alunos, de acordo com níveis de } \\
\text { aproveitamento estabelecidos. }\end{array}$ \\
\hline
\end{tabular}

Fonte: Adaptação de Haydt, 2004.

Para tanto, como citado no Quadro 1, e considerando as perspectivas dos três docentes sujeitos da pesquisa a avaliação pode ser identificada como somativa atribuindo notas aos educandos. Assim, o único intuito da avaliação são as notas para boletins nos finais de bimestres e/ou semestres com base em padrões preestabelecidos, como por exemplo, gabaritos de provas e padrões de comportamento ideal de alunos.

Santos (2005) se refere à avaliação somativa como aquela cuja função é julgar e classificar o aluno segundo seu aproveitamento ao final de uma unidade correspondendo as abordagens de uma avaliação cuja finalidade é a medição da aprendizagem relatada pelos professores entrevistados. De modo igual, Preite (2010) e Freitas, Costa e Miranda (2014) enfatizam que são os atos avaliativos de função 
Pesquisa em Foco ISSN (2176-0136)

http://ppg.revistas.uema.br/index.php/PESQUISA EM FOCO

São Luís, v. 22, n. 2, Jul./Dez. 2017

somativa que dominam o cenário do sistema de avaliação das escolas, negando a dinâmica do processo avaliativo.

Pela necessidade de estabelecer as conexões entre as funções e os recursos utilizados pelos professores em seus atos avaliativos nas salas de aula, efetuou-se a indagação: qual instrumento de avaliação você mais utilizada? E por quê?

Nessa questão, os três professores entrevistados apresentaram semelhanças em seus instrumentos avaliativos, como descritos no Quadro 2.

Quadro 2 - Instrumentos avaliativos utilizados pelos professores.

\begin{tabular}{|c|c|}
\hline PROFESSORES & INSTRUMENTOS \\
\hline$A$ & Lista de exercício, trabalhos, provas \\
\hline B & $\begin{array}{c}\text { Questionários avaliativos de linguagem } \\
\text { (atualizados) e prova escrita (redação } \\
\text { avaliativa) }\end{array}$ \\
\hline C & $\begin{array}{l}\text { Provas, seminários, jogos de perguntas e } \\
\text { respostas }\end{array}$ \\
\hline
\end{tabular}

Fonte: Dados de pesquisa.

Os instrumentos de avaliação de acordo com Gonçalves e Larchert (2012) são os procedimentos e técnicas de ensino didáticas usadas no decorrer do trabalho docente. Como mostrado no quadro 2 fica evidente quais são os instrumentos avaliativos utilizados pelos professores no Centro de Ensino Senador Clodomir Millet, apoia-se nas concepções pedagógicas para a quantificação da aprendizagem com o intuito de atribuir notas.

Percebe-se a uniformidade das provas como principal meio para determinar as notas. Depresbiteris e Tavares (2009) apontam que são várias as críticas sobre a qualidade das provas enquanto instrumento avaliativo, por exemplo, cobrança de conteúdos sem significados e grande quantidade de questões, bem como centralizam apenas a memorização de determinados conteúdos descontextualizadas e/ou fragmentados com a realidade. Nessa mesma visão, Perrenoud (1999) afirma que essa tarefa de avaliação trata o aluno somente em sua capacidade de refazer sozinho o que foi visto anteriormente na sala de aula, em período limitado e determinado. 
Para Hoffmann (2008) os instrumentos citados pelos professores entrevistados são e devem ser usados, mas com um olhar de observação e investigação sobre a situação em que se encontra a aprendizagem do aluno, independentemente de serem considerados métodos tradicionais para a avaliação do aluno (MIZUKAMI, 2011). Desse modo, as provas com questões abertas e fechadas, testes, exames escritos quando planejadas e utilizadas nas perspectivas que de avaliação é um momento de reflexão das abordagens tanto do ensino como da aprendizagem, se configuram como meios viáveis para a melhoria do trabalho docente.

Nesta compreensão as provas devem ser cuidadosamente elaboradas e seus resultados não devem ser transformados em juízos final do aluno (ANDRÉ; PASSOS, 2011). Tendo isso em vista, as notas das provas não podem ser usadas como um mecanismo de classificação do professor para a segregação entre o "bom" e o "mau" aluno, portanto, de acordo com Perrenoud (1999) não produzir hierarquias de excelência entre os estudantes.

As notas são apenas formas de expressão dos resultados da aprendizagem, e que o numeral é um símbolo para a comunicação mais fácil e rápida da qual necessita veicular os alcances dos objetivos pré-estabelecidos, informando a respeito da aprendizagem sobre o aluno e de destinatários determinados, como exemplo, os sistemas de avaliação da educação (GRILLO; LIMA, 2010; SAUL, 2010).

Acrescenta-se, ainda, que a prova mantenha o seu grande valor como recurso máximo de avaliação do aprendizado, pois o Centro de Ensino Senador Clodomir Millet possui em seu calendário escolar semanas reservadas para as aplicações de suas provas avaliativas da aprendizagem. Vasconcellos (2008) expõe que realizações periódicas prédefinidas reforçam concepções de avaliações classificatórias nas quais o ideal seria que as suas execuções fossem marcadas, ou seja, "negociadas" diretamente entre os professores e alunos. Do ponto de vista de Perrenoud (1999) a característica constante de submeter os alunos a provas e/ou exames periódicos evidenciam uma avaliação tradicional, comparativa e individual.

O que se verificou também na fala do professore $C$ foram à utilização dos jogos de perguntas e respostas e listas de exercícios como instrumento avaliativo. Vasconcellos (2008) considera isso como uma maneira de auto-avaliação pelos alunos, 
Pesquisa em Foco ISSN (2176-0136)

http://ppg.revistas.uema.br/index.php/PESQUISA EM FOCO

São Luís, v. 22, n. 2, Jul./Dez. 2017

pois os próprios estudantes elaboram sua avaliação. Com isso, ao elaborarem as sugestões de questões (ou propostas de trabalhos) estão estudando e ao mesmo tempo dando elementos para o professor analisar se captaram o que é essencial dos conteúdos conceituais trabalhados.

Nas respostas sobre o porquê da escolha desses instrumentos avaliativos, se verificou, de modo geral, os seus usos por serem de fácil acesso e elaboração. Grillo e Lima (2010) afirmam que o professor que utiliza diferentes instrumentos avaliativos reconhece que a avalição é processo acumulativo, consequentemente oportunizam maneiras variadas dos alunos expressarem suas aprendizagens.

Evidentemente, como existem diferentes tipos de aprendizagem são necessárias também distintas formas de avaliação para que possa ocorrer a sua validação de maneira mais democrática. Hoffmann (2008) destaca que isso é essencial, pois através de diferentes formas avaliativas o docente compreende que os instrumentos são elementos que podem orientar e desafiar também os alunos para o avanço em seus conceitos.

A avaliação da aprendizagem traz consigo a indispensabilidade da definição dos critérios que devem ser considerados no processo avaliativo dos alunos no decorrer da utilização de seus instrumentos, sendo assim, perguntou-se aos professores: quais são os seus critérios de avaliação?

As discussões obtidas para os professores A, B e C foram: realização das atividades, participações das aulas e entrega de atividades. Vasconcellos (2008) constata que atuações dos estudantes nos trabalhos em sala de aula são contingências que servem para melhorar as condições de aprender na sala de aula e, para tanto, deve está enraizada em critérios bem definidos.

Gessinge, Grillo e Freitas (2010) em seus estudos sobre critérios de avaliação a serviço da aprendizagem os categorizaram diante das funções do ato avaliativo formativo (critérios de realização) e da somativa (critérios de resultados), como descritos no Quadro 3. 
Quadro 3 - Critérios de realização e de resultados.

\begin{tabular}{|c|lr|}
\hline Critérios & \multicolumn{1}{|c|}{ Definição } \\
\hline Realização & $\begin{array}{l}\text { Relação direta com o processo de aprendizagem e tornam } \\
\text { explícitas as condições de aceitabilidade dessa aprendizagem }\end{array}$ \\
\hline \multirow{3}{*}{ Resultados } & $\begin{array}{l}\text { Relação com os produtos alcançados e indicam as condições de } \\
\text { aceitabilidade } \\
\text { desempenhos esperados do aluno em tarefas mais } \\
\text { abrangentes, conclusivas } \\
\text { mais longo prazo. }\end{array}$ & e cer \\
\hline
\end{tabular}

Fonte: Adaptação de Gessinge, Grillo e Freitas, 2010. p.39-40.

Os instrumentos de avaliação utilizados pelos professores do Centro de Ensino Senador Clodomir Millet (ver Quadro 2) podem ser classificados dentro da categoria dos critérios de realização, tendo em vista, que são representados pelas ações concretas que resultam do desenvolvimento das atividades dos alunos na sala de aula. Com esses aspectos, os critérios avaliativos são imediatos e de alcance mais próximo e rápido aos discentes (GESSINGE; GRILLO; FREITAS, 2010).

Porém, os critérios de resultado, assim como da função somativa da avaliação, o foco é somente nos produtos obtidos ao final do processo. Nestas condições, os professores operacionalizam os valores do término da produtividade dos alunos a partir dos usos dos instrumentos avaliativos. Com isso, tais critérios são caracterizados, sobretudo, em planos de ensino e das unidades dos conteúdos (GESSINGE; GRILLO; FREITAS, 2010).

A explicação dos critérios, dessa forma, torna-se fundamental e útil para melhor direcionar os caminhos para uma prática pedagógica avaliativa reflexiva na medida em que ambos podem ser utilizados para o aperfeiçoamento da avaliação da aprendizagem e do trabalho docente.

Além disso, os critérios de avaliação são dinâmicos. Assim, cada professor introduz seus conceitos subjetivos em suas respectivas áreas de ensino, para o estabelecimento de seus critérios avaliativos. Por exemplo, para o educador de Matemática os parâmetros podem ser a capacidade da resolução de determinada equação, para a Língua Portuguesa, as habilidades em intepretação de textos, gramática e ortografia, e para a Biologia a compreensão e explicações de funções biológicas. 
Pesquisa em Foco ISSN (2176-0136)

http://ppg.revistas.uema.br/index.php/PESQUISA EM FOCO

São Luís, v. 22, n. 2, Jul./Dez. 2017

É valido, mediante isso, que os critérios de avaliação circundam as áreas de conhecimento e representam, segundo Gessinge, Grillo e Freitas (2010) os conhecimentos científicos de cada disciplina dentro de seus objetivos. Logo, normas para as avaliações também dependem das características das disciplinas exigindo para cada área de conhecimento critérios distintos e, dentro desse contexto, o professor deve refletir como estabelecer os parâmetros considerando que os valores para a medição de uma aprendizagem perpassam pela sua subjetividade e são multidimensionais.

Em meio às relações dos critérios de avaliação, para a quantificação da aprendizagem dos alunos, através das notas foi realizada a seguinte pergunta aos professores: com base em que você atribui notas para seus alunos?

Os discursos dos três professores contemplam que o ponto de partida para atribuição de notas são os aspectos qualitativos e seguindo os critérios qualitativos e quantitativos, gerando as notas. Sobre essa questão, Saul (2010) caracteriza que a abordagem qualitativa no processo avaliativo as considerações são unicamente voltadas para as observações do comportamento dos alunos com o propósito da mensuração.

Além disso, pelas descrições dos professores os instrumentos avaliativos utilizados são outros meios para os quais se atribui as notas e/ou pontos para os alunos. Luckesi (2011) destaca que usualmente nas escolas brasileiras as práticas avaliativas correspondem em acertos e erros nas provas ou outros meios para a coleta de resultados, diante disso, o caráter de mediação da aprendizagem dos alunos tem como início os pontos atribuídos pelas atividades. Essa prática de avaliação orienta aos alunos a uma visão simplicista que o verdadeiro resultado da aprendizagem são as notas e, com isso o seu envolvimento nas atividades pode se restringir somente se os fatores qualitativos forem quantificados para a sua nota final.

As notas finais são formas de registrar a aprendizagem dos alunos através, principalmente de números adotadas por escolas com abordagens puramente tradicionais (HOFFMANN, 2008; MIZUKAMI, 2011). Ao mesmo tempo em que para Hoffmann (2008) o sistema de notas escolares brasileiro não serve como indicadores 
para a ação mediadora do professor, isso em decorrência de sua superficialidade para representar a aprendizagem do aluno e limitá-lo ao um simples número.

No entanto, os sistemas educacionais ao estabelecerem normas, parâmetros e diretrizes para o processo avaliativo do aluno tende a especificar e normalizar como deve ocorrer a avaliação, o que implica na maneira constante das formas que o professor avalia seus alunos, bem como da elaboração utilização dos instrumentos avaliativos (PERRENOUD, 1999).

Outra crítica discutida por Hoffmann (2008) é a subjetividade dos professores no ato da atribuição de notas. Nesse processo, Luckesi (2011) simboliza a avaliação como um ato de julgamento em que o professor em seu caráter afetivo aos alunos os distingue em certo e errado na qual ocorre a inclusão do primeiro e a exclusão do segundo nos processos de ensino e aprendizagem.

Com o estabelecimento do ensino centralizado no resultado final, ou seja, nas notas e não na aprendizagem dos alunos reflete também, conforme Gonçalves e Larchert (2012), que o sistema social se contenta com as notas excluindo sua preocupação com o futuro, isto é, com o aprendizado dos discentes para uma formação cidadã.

Tendo em vista, que a avaliação é uma maneira de indicar os avanços e dificuldades dos alunos quanto a sua aprendizagem e que também permite ao professor um olhar para suas metodologias adotadas em sala de aula averiguou-se: quando você percebe que a maioria dos seus alunos não aprendeu algum conteúdo, o que você costuma fazer?

A recuperação foi considerada pelos três professores como o método mais utilizado para a reavaliação da aprendizagem dos estudantes. Lima e Grillo (2010) definem o processo avaliativo de recuperação de uma disciplina como um conjunto de atividades didáticas propostas pelo professor cuja função é reorientar o percurso da aprendizagem do aluno, suprindo as lacunas e retornando aos objetivos préestabelecidos.

O processo de recuperação, diante disso, resulta entre o professor e o aluno, este como aprendeu e aquele como ensinou. Desse modo, o objetivo é alcançar o resultado satisfatório do ensino e aprendizagem. Em contradição, Vasconcellos (2008) 
Pesquisa em Foco ISSN (2176-0136)

http://ppg.revistas.uema.br/index.php/PESQUISA EM FOCO

São Luís, v. 22, n. 2, Jul./Dez. 2017

trata as abordagens da recuperação com certa ambiguidade devido às condições objetivas de trabalho dos professores. Dessa maneira não realiza devidamente sua função em decorrência, por exemplo, da carga horária extensa dos professores que, de modo geral, não permite o acompanhamento do aluno na construção de seu conhecimento, sobretudo daqueles que têm maior dificuldade em determinados assuntos.

De acordo com Lima e Grillo (2010), as atividades de recuperação deveriam ser um processo contínuo, porém são realizadas, principalmente, nos finais das unidades de conteúdos estabelecidos pelos cronogramas, o que contradiz com as concepções de uma avaliação diagnóstica. Mediante isso, expressa novamente que as escolas brasileiras trabalham com a verificação da aprendizagem, preconizado por Luckesi (2011). Trata-se, assim, que as recuperações no Centro de Ensino Senador Clodomir Millet reforçam sua função somente para a medição, quantificação e classificação da aprendizagem.

Após o conhecimento das concepções dos conceitos, funções e instrumentos da avaliação da aprendizagem em sala de aula apresentados pelos professores, questionou-se: o que mais incomoda você no processo avaliativo?

Os três professores relataram que a falta de interesse dos alunos, o não retorno positivo dos conteúdos ministrados e a indisciplina dentro da sala de aula como as principais os principais causas de incômodos no trabalho docente. Sobre a indisciplina em uma perspectiva avaliativa Vasconcellos (2005) ressalta que o uso das notas é, frequentemente, utilizado com tons de ameaça, com isso distorcendo o sentido da avaliação.

Além disso, conforme Souza (2003) ocorre a tendência entre os profissionais da educação de sempre culpar o aluno pelo seu sucesso e/ou fracasso no rendimento escolar como se ele fosse o único responsável pelo processo de ensino e aprendizagem. Tudo isso, para Preite (2010) faz com que os próprios alunos também coloquem a culpa em si mesmos e declarem que estão satisfeitos com os processos avaliativos a que estão submetidos. 
Diante disso, também reflete a presença de uma relação de autoritarismo no contexto da avaliação, conforme Saul (2010) e Luckesi (2011). Para Freitas, Costa e Miranda (2014) denotam o processo avaliativo usado como uma forma de punição e controle social.

\section{CONCLUSÕES}

As respostas dos questionamentos e análises das percepções dos professores corresponderam à hipótese levantada no estudo, pois denotaram que os conceitos e práticas da avaliação da aprendizagem de educadores do Centro de Ensino Senador Clodomir Millet é caracterizada como um ato avaliativo para a verificação no processo de ensino e aprendizagem, por conseguinte, uma função somativa visando à classificação do corpo discente em reprovados e aprovados.

Os instrumentos de avaliação seguindo os critérios de realização configuram-se como formativos na medida em que buscam elucidar o nível de aprendizagem dos alunos. Por outro lado, é restrita e, de modo geral, a aplicação de provas escritas ocasionando uma prática avaliativa estática, sendo assim ausente de um exercício com o intuito de reflexão e reorganizações das abordagens de ensino do professor.

Por fim, apesar do número reduzido de professores participantes do estudo, este artigo explora com um olhar na abordagem fenomenológica das concepções de avaliação da aprendizagem dos professores, traçando dessa maneira, paralelos entre a teoria e a prática. Com isso, contribui com debates e reflexões sobre a ação pedagógica dos docentes, proporcionando uma melhor atuação desse profissional.

Além disso, possibilita futuras pesquisas sobre percepções da avaliação escolar, pois o processo de aprendizado não é totalmente responsabilidade do professor, tendo em vista que a coordenação da escola e alunos, também são agentes envolvidos nos processos avaliativos e no desenvolvimento do ensino e aprendizagem.

\section{REFERÊNCIAS}

ANDRÉ, M. E. D. A. PASSOS, L. F. Avaliação escolar: desafios e perspectivas. In: CASTRO, A. D.; CARVALHO, A. M.P. (Orgs.). Ensinar a ensinar: Didática para a escola fundamental e média. São Paulo: Cengage Learning, 2011. p. 177-195. 
Pesquisa em Foco ISSN (2176-0136)

http://ppg.revistas.uema.br/index.php/PESQUISA EM FOCO

São Luís, v. 22, n. 2, Jul./Dez. 2017

BRASIL, Lei de Diretrizes e Bases da Educação Nacional: lei n. 9.394, de 20 de dezembro de 1996, que estabelece as diretrizes e bases da educação nacional. Disponível em: <http://www.planalto.gov.br/ccivil_03/leis/L9394.htm>. Acesso em: 28 ago. 2017.

BRASIL, Ministério da Educação. Instituto Nacional de Estudos e Pesquisas Educacionais Anísio Teixeira (Inep). Indicadores educacionais da Educação Básica: Taxas de rendimento das escolas. Brasília, 2013.

COSTA, O. A.; CASTRO, S. S. V.; ALMEIDA NETO, J. A. Concepções de avaliação sob a perspectiva dos alunos. In: CONGRESSO NACIONAL DE EDUCAÇÃO, 12, 2015. Anais... Curitiba, 2015.

DEPRESBITERIS, L. TAVARES, M. R. Diversificar é preciso: instrumentos e técnicas de avaliação de aprendizagem. São Paulo: Editora SENAC, 2009.

FONSECA, J. J. S. Metodologia da pesquisa científica. Fortaleza: UEC, 2002.

FREITAS, S. L.; COSTA, M. G. N. MIRANDA, F. A. Avaliação Educacional: formas de uso na prática pedagógica. Meta: Avaliação. Rio de Janeiro, v. 6, n. 16, p. 85-98, jan./abr. 2014.

GESSINGER, R. M.; GRILLO, M. C.; FREITAS, A. L. S. Critérios de avaliação a serviço da aprendizagem. In: GRILLO, M. C.; GESSINGER, R. M. (Orgs.). Por que falar ainda em avaliação? Porto Alegre: EDIPUCRS, 2010. p. 35-44.

GONÇALVES, L.; LARCHERT, J. M. Avaliação da aprendizagem: Ilhéus, BA: EDITUS, 2011.

GRILLO, M. C.; LIMA, V. M. R. Questões sobre avaliação da aprendizagem: a voz dos professores. In: GRILLO, M. C.; GESSINGER, R. M. (Orgs.) Por que falar ainda em avaliação? Porto Alegre: EDIPUCRS, 2010. p. 23- 34.

HAYDT, R. C. Avaliação do processo de ensino-aprendizagem. 6. ed. São Paulo: Ática, 2004.

HOFFMANN, J. Avaliar: respeitar primeiro, educador depois. Porto Alegre: Mediação, 2008.

LUCKESI, C. C. Avaliação da aprendizagem escolar: estudos e proposições. 22. ed. São Paulo: Cortez, 2015.

MIZUKAMI, M. G. N. Ensino: as abordagens do processo. São Paulo: EPU, 2011. 
PERRENOUD, P. Avaliação: da excelência à regulação das aprendizagens-entre duas lógicas. Patrícia Chittoni Ramos [tradução]. Porto Alegre: Artmed, 1999.

PREITE, N. Z. A avaliação nos processos de ensino e aprendizagem: concepções de professores da rede pública de ensino. 2010. 73f. Monografia (Graduação em Licenciatura em Ciências Biológicas). Universidade Presbiteriana Mackenzie. São Paulo, 2010.

SANTOS, C. R. Avaliação educacional: análises conceitual, legal e crítica. In: SANTOS, C. R. (Org.); FERREIRA, M. C. I. (Coord.). Avaliação educacional: um olhar reflexivo sobre a sua prática. São Paulo: Avercamp, 2005, p. 21-43.

SAUL, A. M. Avaliação emancipatória: desafio à teoria e a prática de avaliação e reformulação do currículo. 8. ed. São Paulo: Cortez, 2010.

SOUZA, S. Z. L. A prática avaliativa na escola de ensino fundamental. In: SOUSA, C. P. (Org.). A avaliação do rendimento escolar. 11. ed. Campinas: Papirus, 2003. p. 83-108.

TRIVIÑOS, A. N. S. Introdução à pesquisa em ciências sociais: a pesquisa qualitativa em educação. São Paulo: Atlas, 2015.

VASCONCELOS, C. S. Avaliação: concepção dialética-libertadora do processo de avaliação escolar. 18. ed. São Paulo: Libertad, 2008. 